\title{
Supplemental Figures.
}

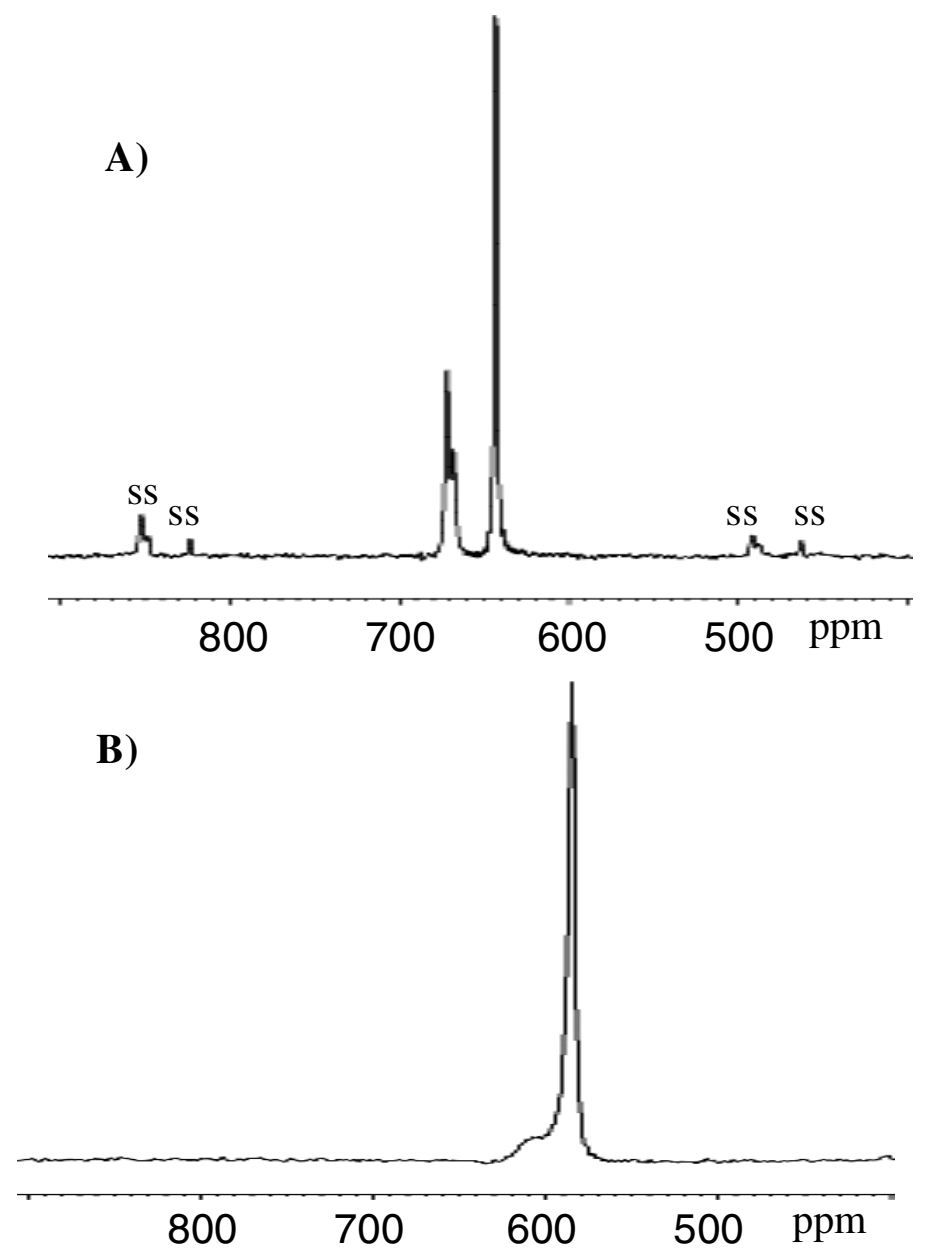

Supplemental Figure 1. A. ${ }^{113} \mathrm{Cd}$ CPMAS NMR of the precursor, $\mathrm{Li}_{4}\left[\mathrm{Se}_{4} \mathrm{Cd}_{10}(\mathrm{SPH})_{16}\right]$. The peak at $643 \mathrm{ppm}$ represents cadmiums tetrahedrally coordinated to thiophenol. The peaks at 668 and $672 \mathrm{ppm}$ represent axial and equitorial cadmium, respectively, that are coordinated to selenium and thiophenol; the spinning sidebands of these cadmiums are marked with ss. (Lee, G. et al. Inorg. Chem. 1993, 32, 66-72.)

B. ${ }^{113} \mathrm{Cd}$ Hahn echo NMR of bulk hexagonal CdSe. 


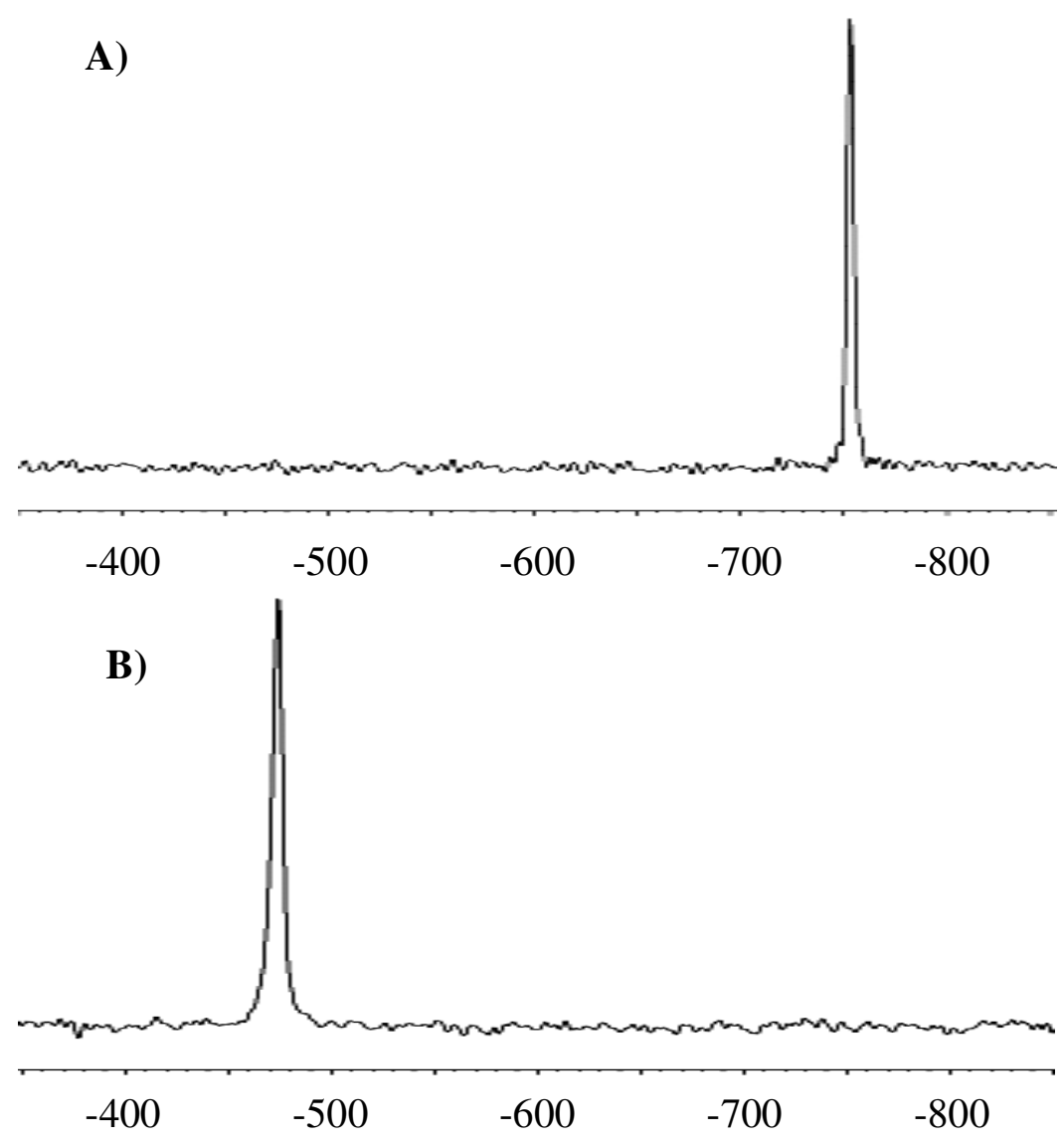

Supplemental Figure 2. A. ${ }^{77} \mathrm{Se}$ CPMAS NMR of the precursor, $\mathrm{Li}_{4}\left[\mathrm{Se}_{4} \mathrm{Cd}_{10}(\mathrm{SPH})_{16}\right]$. B. ${ }^{77} \mathrm{Se}$ Hahn echo NMR of bulk hexagonal CdSe. 
Supplemental Figure 3. The integrated ${ }^{77} \mathrm{Se}$ peak intensities from ${ }^{1} \mathrm{H}^{-77} \mathrm{Se}$ CPMAS were plotted as a function of contact time, $\tau$. The plot was fit to equation 1 using a nonlinear least squares analysis to determine the cross-relaxation time constants, $T_{\mathrm{SeH}}$.
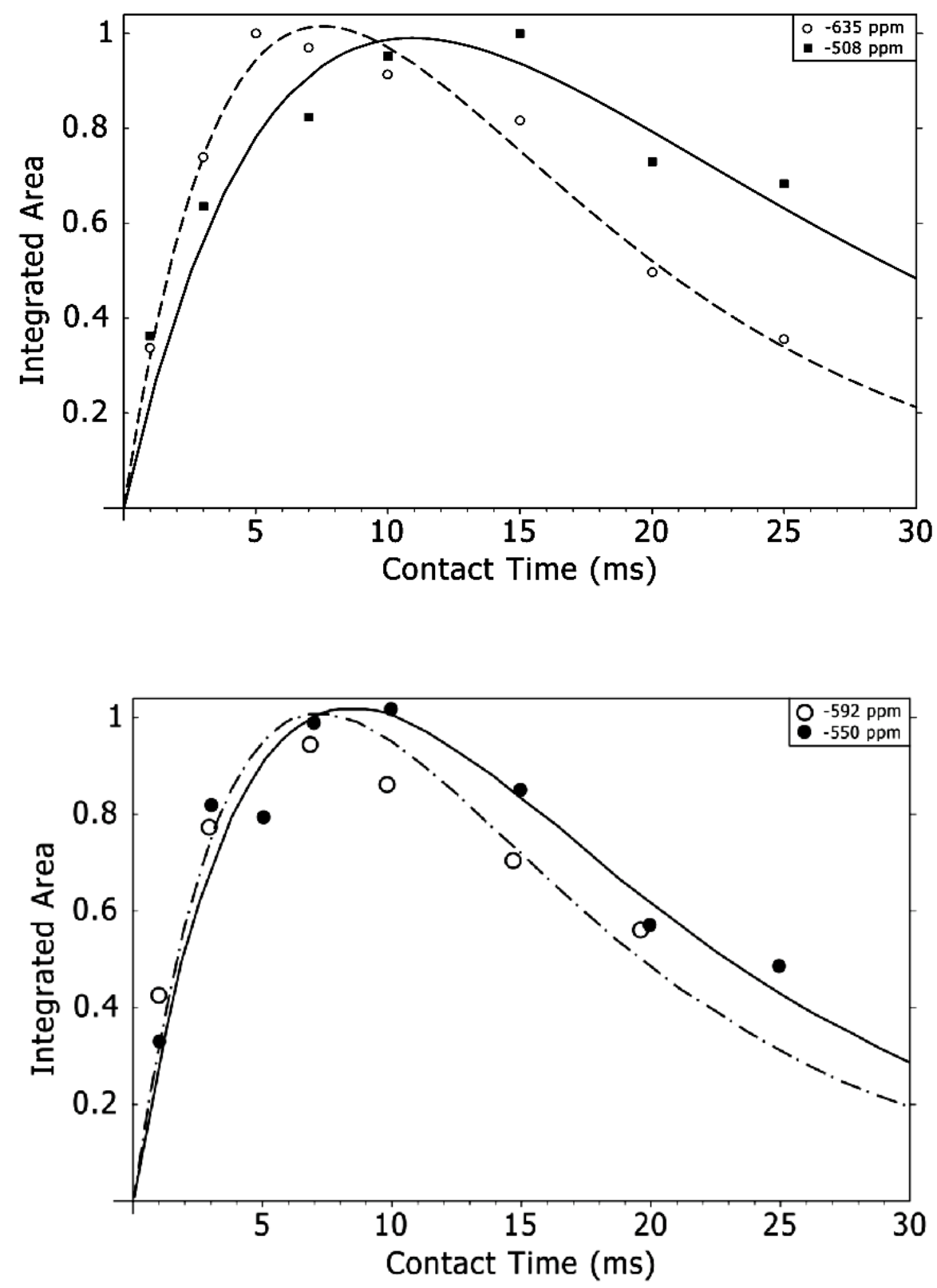
